\title{
David Oliver: Incendiary healthcare hashtags
}

\author{
David Oliver consultant in geriatrics and acute general medicine
}

Berkshire

I probably spend too much time on "healthcare" Twitter. Twitter is a fantastic place for learning, sharing, networking, and debate. It can be compulsive and distracting, joyous, warm, and enlightening. It's also sometimes fractious, factional, and shouty, leaving users upset. The ongoing saga of the \#doctorsaredickheads hashtag is a prime example.

Healthcare workers, researchers, reporters, and policy makers can use Twitter to engage directly with people who use services and with the wider public, who in turn use Twitter for peer support, discussion, lobbying, and speaking directly to people in power (including clinical professionals). They also use it for sharing experiences of illness, including frustrations with health services. Sometimes on Twitter these professional and patient circles intersect and something sparks, as with \#doctorsaredickheads.

This hashtag seems to have started as a tweet in response to posts by Stevie Boebi about her experiences with her Ehlers-Danlos syndrome, including a long wait for diagnosis and doctors' repeated dismissal of her symptoms. The spark quickly ignited and spread internationally, such as when an Australian writer, Asher Wolf, tweeted about her own similarly distressing experiences.

My unscientific sample of the tweets that then set the hashtag ablaze suggests that most of the posters were female, often from ethnic minorities, and often with a physical disability or longstanding mental health problem. Ehlers-Danlos syndrome featured prominently, especially regarding long delays in diagnosis and expert support. Other problems doctors seemed to find it hard to recognise or treat included chronic pain, chronic fatigue syndrome and fibromyalgia, endometriosis, irritable bowel syndrome, Lyme disease, and dysautonomia.

Some patients said that many doctors had dismissed patients' own expertise in living with a condition, trivialised their symptoms, and even abused or "gaslighted" them—dismissing them as hypochondriacs and troublemakers. The doctors they saw may well have a different narrative, but confidentiality and professional rules mean that we'll never know. Even so, we can't dismiss or invalidate those patients' accounts, experiences, and feelings.
This degree of rancour will not help to make services more person centred or inclusive

Members of the public weighed in to praise doctors who had helped them, and they criticised the incendiary language of the hashtag. Though many posts were from outside the UK, NHS doctors pointed out that they were public servants in an overwhelmed and depleted service, doing the best they could. Burnout and poor morale won't be helped by inflammatory language.

Before long some related hashtags started side fires, such as \#doctorsarehuman and \#doctorsirespect-and, more worryingly, \#patientsaredickheads.

Some doctors thought that their professionalism, competence, integrity, and dedication were being attacked and said that people didn't understand the conditions they work in. Healthcare staff often felt powerless and overwhelmed, they said: mental health problems and suicide were high among doctors, who were often patients, carers, or parents too. This hashtag wouldn't help them.

The \#doctorsaredickheads hashtag certainly got people talking. It gave people a voice and some peer solidarity, it attracted comment, and it simultaneously engaged, antagonised, distanced, and upset doctors. There's much to be learnt if doctors are prepared to get beyond the inflammatory language, read the patients' stories, and avoid trying to defend or attack. But in the long run, I suspect that this degree of rancour will not help to make services more person centred or inclusive, more prepared to listen to feedback, or more willing to engage with patients.

Social media can sometimes cause more heat than light. In this case I wonder whether, if those arguing online had been sitting in the same room discussing the issues in person, the flames of anger would have diminished and some mutual understanding would have emerged as the fire was damped down. Online, it became a conflagration.

Competing interests: See www.bmj.com/about-bmj/freelance-contributors/davidoliver

Provenance and peer review: Commissioned; not externally peer reviewed. 
Published by the BMJ Publishing Group Limited. For permission to use (where not already granted under a licence) please go to http://group.bmj.com/group/rights-licensing/

permissions 